\title{
Upaya Menghadapi Cuaca Buruk (Typhoon) Guna Mencegah Terjadinya Kecelakaan Pelayaran di Kapal MV. Pan Kristine
}

\author{
Eka Budi Tjahyono ${ }^{1}$, Fahmi Umasangaji ${ }^{2}$, Leonardo Prakarsa ${ }^{3}$ \\ ${ }^{1,2,3}$ Prodi Ketatalaksanaan Angkutan Laut dan Kepelabuhanan \\ Sekolah Tinggi Ilmu Pelayaran, Jakarta \\ Jl. Marunda Makmur No. 1 Cilincing, Jakarta Utara. Jakarta 14150
}

\begin{abstract}
Abstrak
Kecelakaan pelayaran terus meningkat disertai korban meninggal/hilang dan luka-luka cukup banyak. Penyebab kecelakaan bervariasi ada yang disebabkan kesalahan manusia, muatan lebih, pengelolaan angkutan, faktor teknis, dan faktor alam, namun penyebabnya tidak selalu tunggal tetapi kebanyakan kombinasi dan faktor yang dominan adalah kesalahan manusianya (human error) sebanyak $88 \%$. Semua kapal mempunyai resiko terjadinya musibah/kecelakaan pelayaran, apakah kapalnya kandas/karam, tenggelam, tubrukan, dan terbakar. Untuk itu diperlukan segala daya upaya untuk mengatasi kemungkinan terjadinya musibah/kecelakaan pelayaran, termasuk Kapal MV PAN Kristine yang sedang lego jangkar di anchorage Pelabuhan Zhousan Cina untuk menunggu doking melakukan perawatan ringan yang menghadapi cuaca buruk (typhoon) dan kondisi pengkait/pengikat (lashings) yang tidak terawat dengan baik, yang di dalam pelayaran tersebut terdapat Cadet Leonardo Prakarsa ikut dalam pelayaran sebagai pelaut yang mengikuti Praktek Laut. Penelitian ini bertujuan untuk mengetahui dan menghadapi langkah yang diperlukan dalam menghadapi cuaca buruk (typhoon) serta untuk mengetahui kondisi lashings ketika kapal terkena akibat tidak langsung dari pusat typhoon karena kapal sempat menjauh dan langkah perawatannya. Penelitian ini menggunakan pendekataan kualitatif karena Peneliti terlibat langsung dalam peristiwa serangan typhoon dengan mengumpulkan data melalui observasi dan wawancara dengan Nokhoda dan dan perwira jaga setelah peristiwa tersebut, melalui model penelitian studi kasus. Teknik analisis yang digunakan adalah model fault tree analysis (FTA). Dalam penelitian dihasilkan temuan ketidaksiapan secara teknis dan manajerial dari awak kapal ketika terjadi cuaca buruk yang tidak diperkirakan sebelumnya dalam pelayaran mengangkut muatan maupun pada saat menunggu jadwal doking karena kasusnya pada saat itu kapal memang sedang lego jangkar di anchorage di Pelabuhan Zhousan Cina
\end{abstract}

Copyright $($ ) 2020, Prosiding Seminar Pelayaran dan Riset Terapan

Kata Kunci: thypoon, mencegah, kecelakaan, kapal

Permalink/DOI : https://doi.org/10.36101/pcsa.v2i1.126

\section{PENDAHULAN}

Berdasarkan hasil penelitian Konsultan PT. Trans Asia kerjasama dengan Komite Nasional Keselamatan Transportasi (KNKT) menyatakan bahwa musibah/kecelakaan pelayaran kecenderungan selama 5 (lima) tahun sejak 2003 s.d 2008 masih cukup tinggi rata-rata meningkat sebanyak 17\% pertahun (Laporan Akhir Penelitian PT Trans Asia Consultant:2009:42). Hal di atas juga sejalan dengan Laporan KNKT mengenai Hasil Investigasi Kecelakaan Transportasi dan Monitoring Rekomendasi Keselamatan Transportasi Tahun 2015-2020. Selama periode tersebut KNKT telah melakukan investigasi kecelakaan pelayaran sebanyak 132 investigasi, dalam hal ini investigasi terbanyak yang dilakukan pada tahun 2018 sebanyak 39 investigasi dengan jumlah korban yang meninggal dan hilang sebanyak 73 orang pada tahun 2015,63 orang pada tahun 2016, 52 orang pada tahun 2017, 299 orang pada tahun 2018, 92 orang pada tahun 2019, dan pada tahun 2020 belum terdata (Laporan Investigasi KNKT:2020).

Menurut Bayu Mardianto, terjadinya musibah/kecelakaan pelayaran dikarenakan beberapa faktor yaitu, kesalahan manusia (human error), kelebihan kapasitas, teknis, pengelolaan lalu lintas kapal, dan alam (https://www.kabar penumpang). Hal tersebut juga diperkuat dengan hasil inventarisasi kecelakaan di wilayah 
kesyahbandaran Tanjung Priok periode 2014 s.d 2016 yang terdapat 18 kecelakaan yang diakibatkan faktor alam 7 kecelakaan, faktor lainnya 5 kecelakaan, dan faktor manusianya 6 kecelakaan. Faktor alam mempunyai kontribusi terbesar karena adanya alur yang sempit sedangkan tingkat kepadatan lalu lintas cukup tinggi yang terkait dengan kehati-hatian awak kapal/manusianya dalam melayari alur tersebut (Harnoli Rahman dkk:2017:279-280). Faktor terbesar penyebab musibah/kecelakaan pelayaran adalah kesalahan manusia (human errar) sebesar $88 \%$, sedangkan karena faktor alam $8 \%$ dan faktor lainnya 4\% (Laporan Akhir Penelitian PT Trans Asia:2009:30). Faktor kesalahan manusia (human error) sebesar $88 \%$ juga dinyatakan oleh Menteri Perhubungan (Suara.com:2016).

Berdasarkan penelitian karakteristik kapal di perairan Indonesia hasil investigasi KNKT penyabab kecelakaan kapal dikarenakan faktor kesalahan manusia (human error) karena pelaksanaan dinas jaga belum sesuai prosedur dan peranan Nakhkoda (Sereati Hasugian: 2017: 235: 236).

Berdasarkan hal-hal tersebut di atas penyebab musibah/kecelakaan memang kebanyakan tidak hanya tunggal tapi faktor kesalahan manusia (human error) memberikan kontribusi yang besar karena faktor teknik, faktor pengelolaan lalu lintas kapal, muatan lebih, kebanyakan juga karena ada kontribusi kesalahan dari manusianya baik karena kelalaiannya, kecerobohannya, kesengajaannya dan tingkat kompetensinya. Penelitian Widarbawo dalam Laporan Hasil Penelitian PT. Trans Asia (Laporan Hasil Penelitian:2009:28) menyampaikan analisis kompetensi awak kapal $54,7 \%$ perwira kapal tidak sesuai dengan kompetensi yang didapatkan.

Semua kapal yang melakukan pelayaran memiliki resiko menghadapi musibah/kecelakaan pelayaran, termasuk kapal MV. PAN KRISTINE merupakan kapal di bawah manajemen POS SM CO., LT berbendera Korea yang yang mengangkut muatan muatan curah. Untuk itu semua kapal harus mengantisipasi dengan memperkecil resiko penyebab musibah/kecelakaan dengan memenuhi segala ketentuan, prosedur, penyiapan manajemen keselamatan, bridge resource team management, kesiapan kompetens awak kapal terutama Nakhkoda yang akan memimpin dan mengendalikan perjalanan kapal.

Kapal MV PAN KRISTINE adalah salah satu kapal yang mengalami musibah/kecelakaan pelayaran karena terdampak kondisi alam adanya cuaca buruk (typhoon) karena kapal sedang anchorage menunggu doking kecil di Pelabuhan Zhousan China yang dalam hal ini Penulis menglami langsung kejadian tersebut Ketika melaksankan Praktek Laut. Kapal pada saat posisi anchorage berada dalam posisi di titik pusat siklon atau typhoon yang akan dilintasi typhoon tersebut.

Setelah kapal menerima kabar adanya typhoon yang melewati lokasi anchorage kapal belum meninggalkan lokasi yang seharusnya dilakukan pada tanggal 6 Agustus 2019. Kapal baru meninggalkan lokasi dilaluinya typhoon pada tanggal 8 Agustus dengan persiapan yang minim yaitu hanya melakukan mesin untuk manuver. Kapal tidak merencanakan strategi mengenai persiapan dan kesiapan keberangkatan kapal guna menjauh dari titik pusat typhoon agar dapat meminimalisir kerusakan yang dipengaruhi oleh typhoon dikarenakan tidak adanya pelaksanaan bridge resource team management mengenai keberangkatan kapal dan persiapan kapal untuk menghadapi typhoon atau cuaca buruk, sehingga kapal mendapatkan dampak yang cukup besar dimana kapal mengalami rolling pada sudut yang besar bahkan mengalami kerusakan pada plat windlass yang dapat menghambat pengoperasian kapal saat lego jangkar.

Kerusakan plat windlass juga diperparah dengan lemahnya perawatan pada peralatan lassing tersebut. Keberhasilan dari pelaksanaan bridge resource team management dalam perencanaan strategi dan persiapan dalam menghadapi cuaca buruk dapat memperkecil resiko seperti rolling dalam sudut aman serta kerusakan pada bagian kapal seperti plat windlass dan bagian kapal yang mudah berpindah maupun rusak yang disebabkan oleh tingginya tekanan udara dan tinggi alun atau gelombang yang memiliki dorong sehingga dapat merusak beberapa bagian kapal yang dapat membahayakan keselamatan pelayaran.

Berdasarkan hal tersebut peneliti menguraikan identifikasi masalah, yaitu:

1. Belum Optimalnya persiapan dalam menghadapi typhoon (cuaca buruk).

2. Kurang baiknya kondisi plat windlass pada saat menghadapi typhoon (cuaca buruk).

3. Terjadinya keberangkatan yang terlambat guna bergerak sejauh mungkin untuk menghindari cuaca buruk.

4. Tidak optimalnya penerimaan tentang perkiraan cuaca buruk oleh Mualim Jaga.

Kemudian batasan masalah dalam penelitian ini yaitu kesiapan awak kapal dalam berbagi aspek menghadapi typhoon (cuaca buruk) guna mencegah terjadinya kecelakaan pelayaran di MV. PAN KRISTINE.

Berdasarkan uraian yang telah disampaikan dalam latar belakang, peneliti merumuskan permasalahan sebagai berikut: 
1. Bagaimana upaya menghadapi cuaca buruk (typhoon) dalam pelayaran kapal?

2. Bagaimana kondisi perbaikan dan perawatan (repair and maintenance) pada bagian-bagian plat yang mudah berpindah maupun rusak di kapal pada saat terjadi typhoon (cuaca buruk)?

Kemudian tujuan dilaksanakannya penelitian ini yaitu:

1. Untuk mengetahui dan mengevaluasi upaya yang dilakukan dalam menghadapi typhoon (cuaca buruk) dalam pelayaran kapal.

2. Untuk mengetahui persiapan dan kondisi perbaikan dan perawatan pelat kapal ketika hendak dan saat menghadapi typhoon (cuaca buruk) di kapal MV. PAN KRISTIN maupun kondisi normal.

Adapun manfaat penelitian ini secara teoritis adalah dapat memberikan model penanganan yang tepat dalam menghadapi Typhoon (cuaca buruk). Secara praktis, penelitian ini diharapkan dapat memberi masukan kepada perusahaan agar dapat memberikan pengetahuan pada awak kapal dalam memenuhi prosedur persiapan dalam menghadapi cuaca buruk.

\section{METODE}

Metode Pendekatan yang digunakan dalam penelitian ini adalah metode pendekatan deskriptif kualitatif. Dalam memperoleh data peneliti menggunakan teknik pengumpulan data berupa observasi. Observasi adalah pengumpulan data berupa informasi berdasarkan pengamatan langsung oleh peneliti di kapal MV. PAN KRISTINE berbendera Kepulauan Marshall Island milik POS Maritime SC. SA.

\section{HASIL DAN PEMBAHASAN}

Kapal MV Pan Kristine merupakan kapal berbendera asing yang melayari trayek tidak tetap dan tidak teratur (tramper). Pelayaran yang dilakukan oleh kapal tersebut jadwalnya tergantung permintaan untuk dilakukan pemuatannya. Penulis mulai mengikuti trayek perjalanan kapal pada tanggal 8 Agustus 2018 diawali dari Pelabuhan Zhenjiang Cina, menuju Pelabuhan Tokuyama Jepang, Brisbane Australia, Lucinda Australia, Malborne Australia, Bunbury Australia, Qindao China, Donghae Korea, Valadivostok Rusia, Nahkodka Rusia, Manila Philipina.

Kapal selama perjalanannya melakukan pemuatan dan bongkar muat berbagai macam barang (general cargo), antara lain klinker semen, alimunia, gula, plat baja, dan gypsum. Di Philipina kapal melakukan lego jangkar (anchorage) selama 2 (dua) bulan untuk menunggu bongkar muat muatan dan sambal menunggu pelaksanaan doking kapal yang akan dilakukan di Pelabuhan Zhousan China. Doking kapal dilakukan karena diketahui karena lambung timbul dan dinding kapal sudah banyak teritip, beberapa peralatan di dek yang tidak berfungsi secara optimal, kerusakan di kamar mesin, rencana pemasangan peralatan baru ballas water tretmen system, dan kerusakan atau korosi pada plat-plat di dek. Diperkirakan lamanya doking selama 2 (dua) minggu.

Untuk itu kapal melakukan pelayaran menuju perairan Pelabuhan Zhousan dan melakukan lego jangkar (anchorage) di perairan tersebut. Kapal lego jangkar (anchorage) karena menunggu jadwal doking yang akan dilakukan pada tanggal 13 Agustus 2019. Pada saat menunggu jadwal pelaksanaan doking kapal terjadi musibah/kecelakaan kapal karena adanya cuaca buruk (typhoon) yang dapat digambarkan berikut ini.

1. Upaya menghadapi adanya typhoon pada saat kapal lego jangkar.

MV. PAN Kristine berada di pelabuhan anchorage Zhousan, China untuk melaksanakan docking pada tanggal 6 Agustus 2019 dimana Anchorage Area merupakan tempat konsentrasi daerah udara bertekanan rendah dengan perbedaan tekanan yang tinggi, pada saat itu kapal menerima berita mengenai adanya typhoon yang bergerak menuju ke Zhousan, China dengan deskripsi data pelayaran sebagai berikut:

$\begin{array}{ll}\text { Date and Time } & : \text { August, 6th } 2019 \\ \text { Voyage Number } & : \text { DOCKING VOYAGE } \\ \text { From } & : \text { Zhousan Anchorage } \\ \text { To } & : \text { Sheltering Area } \\ \text { Last Port of Call } & : \text { Manila, Philippines } \\ \text { Crew On Board } & : \text { 22 Persons } \\ \text { Loading Condition : Ballast } \\ \text { Pada tanggal 6 Agustus 2019, kapal menerima }\end{array}$ berita dari Weather Facsimile (Japan Meteorologycal Agencies) juga dari Navtex, bahwa terjadi daerah konsentrasi udara bertekanan 930 HPA dan terjadi pembentukan typhoon di bagian utara Taiwan yaitu tepat nya pada posisi $20^{\circ} 38.00$ Lintang Utara $131^{\circ} 34.00$ Bujur Timur di Samudera Pasifik Selatan yaitu tepat diutara Taipei, Taiwan ketika jam jaga mualim 2 yaitu 12:00-16:00

Typhoon yang bernama "LEKIMA" ini bergerak dengan kecepatan $723 \mathrm{Mph}$ atau sekitar dengan 623 knots melalui Selat Taiwan dengan kecepatan angina maksimal 88 knots dipusatnya dan berkcepatan 50 knots dengan radius 70 mil dan 40 knots dengan radius 200 mil, tepatnya dengan rute sebagai berikut:

Perkiraan posisi untuk jam 14:12 UTC pada $23^{\circ} 12.00$ Lintang Utara- $132^{\circ} 06.00$ Bujur Timur dengan radius 80 Mil dari $70 \%$ lingkaran badainya, 
perkiraan posisi untuk jam 15:12 UTC pada $24^{\circ} 54.00$ Lintang Utara- $132^{\circ} 42.00$ Bujur Timur dengan radius 150 Mil dari $70 \%$ lingkaran badainya, perkiraan posisi untuk jam 16:12 UTC pada $24^{\circ} 30.00$ Lintang Utara- $134^{\circ} 00.00$ Bujur Timur dengan radius 220 Mil dari 70\% lingkaran badainya. Samudera Pasifik Selatan - Kepulauan Luzon (Philipina) - Selat Taiwan (Taiwan) - Laut Cina Utara (China) - Selat Korea (Korea Selatan).

Mualim 2 segera melaporkan mengenai berita cuaca tersebut yang diperoleh dari Navtex setempat dan Japan Meteorological Agencies tentang adanya Typhoon "LEKIMA", namun kapal yang pada saat itu hanya menunggu jadwal untuk memasuki docking yard, dibawah order dari Nakhoda kapal harus menunggu dan meyakinkan bahwa kapal akan segera berangkat dibawah instruksi langsung dari Superintendent.

Seharusnya kapal berangkat pada saat itu juga yaitu tanggal 6 Agustus 2019, dimana kapal sudah tidak dalam keadaan yang fit dengan kecepatan 10 knots (pada keadaan baik kapal mampu melaju dengan kecepatan 12 knots) untuk menghindar sejauh mungkin dari Typhoon yang bergerak menuju ke tempat anchorage dimana kapal harus lego jangkar dan menunggu jadwal masuk docking yard. Pada akhirnya kapal berangkat dengan terburu-buru pada tanggal 8 Agustus 2019 dimana kapal hanya melakukan persiapan mesin untuk Maneuvering dan tidak melakukan persiapan lain guna mencegah terjadi nya kerusakan pada bagianbagian kapal.

Tepat sehari setelah keberangkatan kapal pada tanggal 9 Agustus 2019, Nakhoda dan Perwira jaga memantau dimana posisi kapal berada dalam jarak 250 mil dari pusat Typhoon dan memonitor pergerakan typhoon, dan harus melakukan pemeriksaan mengenai pergerakan typhoon setiap 2 jam sekali Pada saat itu kapal mampu melaju dengan kecepatan 8 knots (kecepatan kapal berkurang seiring semakin dekatnya pusat typhoon dengan posisi kapal).

Keesokan harinya pada tanggal 10 Agustus 2019, kapal berada pada jarak yang terlampau dekat dengan typhoon yaitu 180 mil dari pusat typhoon, jarak dengan kecepatan angin antara 40 knots sampai dengan 50 knots. Kecepatan angin dan tekanan yang dihasilkan pada jarak ini dapat menyebabkan gangguan pada stabilitas kapal, juga merusak plat-plat pada kapal.

Pada jarak ini tentunya juga mengurangi kecepatan kapal hingga 2 knots, tekanan pada typhoon "LEKIMA" juga meningkat menjadi 996 HPa hingga kapal yang seharusnya melaju justru kapal mendapat dorongan hingga bergerak mundur karena kecepatan kapal yang minim, namun tingginya tekanan yang kapal dapatkan dari efek jarak dekatnya kapal dengan pusat typhoon.

Hal ini yang dikatakan dengan Dangerous Semi-Circle dimana kapal tidak dapat bernavigasi dengan baik karena pergerakan kapal yang melambat yang disebabkan oleh pusat typhoon sehingga kapal tidak dapat bermanuver dengan baik. Awak dan Perwira jaga juga Nakhoda hanya bisa memantau pergerakan dan perpindahan objekobjek yang memungkinkan untuk pindah maupun rusak melalui anjungan ketika bernavigasi, menerima berita cuaca dengan baik untuk memantau perpindahan juga pergerakan typhoon "LEKIMA" untuk memastikan bahwa kapal menjauh dari pusat typhoon.

Kapal dapat menjauh dan memasuki Navigable Semi-Circle dimana kapal memiliki jarak yang cukup jauh dengan pusat typhoon agar kapal dapat bergerak dan maneuvering menjauh dari typhoon juga memungkinkan bertambahnya kecepatan kapal.

Seiring dengan pergerakan typhoon "LEKIMA" yang semakin mendekat dengan pulau dan menjauh dari kapal, akhirnya typhoon "LEKIMA" bergerak meninggalkan perairan menuju ke China daratan dan menghilang tepat disekitar kota Zhousan (China) pada tanggal 12 Agustus 2019. Kapal dapat kembali ke Zhousan Anchorage tepat waktu yaitu pada tanggal 12 Agustus 2019 untuk menunggu jadwal masuknya kapal ke Zhousan Dockyard.

2. Perbaikan dan perawatan pada plat widslass.

Kondisi kapal yang baik dengan dilakukannya maintenance secara rutin sangat diperlukan diatas kapal terutama saat kapal akan menghadapi cuaca buruk yang berkemungkinan besar dapat merusak kapal apabila tidak dilakukannya pemeriksaan dan maintenance untuk memastikan keaadan kapal terutama di dek berada dalam keaadan baik dan dapat mengurangi bahkan tidak mudah dirusak oleh faktor dari luar kapal seperti kecepatan angin dan tingginya gelombang Pemeriksaan yang dilakukan oleh Nakhoda dan crew kapal untuk memastikan bahwa setiap plat yang berada di dek diperiksa untuk meyakinkan bahwa semua dalam keadaan secured atau dalam keadaan lashings yang baik juga maintained dengan baik sehingga tidak muda rusak ketika kapal menghadapi cuaca buruk.

Sebelum menghadapi typhoon "LEKIMA", Nakhoda dan crew kapal MV. PAN KRISTINE tidak melakukan pengecekan terhadap plat-plat pada bagian deck terutama plat pada windlass, dimana Nakhoda dan mualim jaga juga tidak memberi instruksi kepada deck crew untuk melakukan pengecekan terhadap plat-plat di deck dan jika ditemukan plat yang kondisinya kurang baik dapat dibenahi sesegera mungkin agar tidak terjadi kerusakan, terutama plat pada windlass. 
Apabila plat tersebut rusak atau tidak berada pada posisinya dapat menghambat operasional kapal yaitu ketika akan dilakukan lego jangkar dapat terlambat. Keterlambatan tersebut dikarenakan tidak dilakukannya persiapan dan pemberitahuan kepada anak buah kapal mengenai typhoon yang akan dihadapi kapal dan terjadi keterlambatan ketika berangkat sehingga menyebabkan crew terburu-buru dan tidak melakukan pengecekan juga maintenance pada plat tersebut.

Pada saat kapal sedang menghadapi typhoon "LEKIMA" dan berada dalam dangerous semicircle kapal mengalami keadaan dimana kapal tidak dapat melaju dan didorong mundur untuk jarak yang cukup jauh dikarenakan jarak kapal yang terlampau dekat dengan pusat typhoon yaitu hanya 180 mil dimana seharusnya kapal berada pada jarak minimal 300 mil untuk posisi aman dan tidak mengalami faktor penyebab kerusakan yang begitu besar, sehingga kencangnya angin dan tingginya gelombang menyebabkan kedua plat pada windlass rusak. Hal ini dapat diketahui melalu penglihatan yang dilakukan bridge team saat kapal berada dalam Dangerous Semi-Circle.

Kapal kembali ke Zhousan Anchorage dengan keadaan plat windlass yang belum diperbaiki pada tanggal 12 Agustus 2019, ketika sudah sampai di Zhousan Anchorage kapal harus memperbaiki dahulu plat pada windlass dibawah instruksi Nakhoda dengan dilakukan nya welding oleh Fitter dan dicat kembali oleh Bosun dan ABK kapal tersebut agar dapat melaksanakan lego jangkar sehingga kapal harus drifting terlebih dahulu sampai plat tersebut selesai diperbaiki.

Hal ini yang menyebabkan terhambatnya pengoperasian kapal MV. PAN KRISTINE ketika kembali ke Zhousan Anchorage, karena terjadinya kerusakan yang seharusnya dapat diantisipasi terlebih dahulu sebelum menghadapi cuaca buruk(typhoon).

Setelah diketahui penyebab dari permasalahan yang terjadi dengan berlandaskan pada deskripsi data dari semua permasalahan yang ada, maka pada pembahasan selanjutnya akan dilakukan analisa terhadap permasalahan yang telah digambarkan pada kronologis kerjadi di atas.

Untuk menemukan pemecahan dari masalah di atas dengan melakukan peninjauan dan melakukan perbandingan dengan teori yang ada serta prosedur-prosedur dan persiapan yang dilakukan ketika kapal akan menghadapi cuaca buruk atau typhoon. Berikut ini adalah perincian dari analisa terhadap permasalahan yang ada.

Pertama, pada kejadian yang digambarkan dalam deskripsi data ke 1, ditemukan bahwa apabila setiap terjadi perkembangan yang membahayakan kapal termasuk apabila diterima berita cuaca yang menunjukan adanya pembentukan typhoon yang akan terbentuk di perairan dekat dengan posisi kapal.

Kedua, perwira jaga harus sesegera mungkin memberitahu kepada Nakhoda akan hal tersebut sehingga Nakhoda dapat melaporkan hal tersebut kepada Superintendent dimana kapal akan memasuki doking untuk melakukan perbaikanperbaikan karena kondisi kapal yang sudah tidak fit. Nakhoda dapat melakukan melaksanakan bridge resource team management agar kapal dapat menghindar sejauh mungkin dari pusat typhoon. Awak kapal dapat melakukan maintenance terhadap bagian-bagian pada kapal terutama pada plat di dek agar tidak rusak ketika menghadapi cuaca buruk. Dengan demikin, maka jika tidak dilaksanakan bridge resource team management. Hal tersebut merupakan salah satu dari persiapan ketika kapal akan menghadapi cuaca buruk atau typhoon, Nakhoda dan bridge team dapat memutuskan dan merencanakan strategi keberangkatan kapal untuk menghindar dari titik pusat typhoon sejauh mungkin atau dapat mencapai jarak aman dengan typhoon yaitu 300 mil.

Ketiga, setelah menerima pemberitaan mengenai cuaca dari weather fax juga himbauanhimbauan atau peringatan yang diberikan oleh stasiun pantai atau Marine Department atau Coast Station setempat pada deskripsi dan perwira jaga juga segera melaporkan kabar cuaca tersebut kepada nakhoda. Nakhoda harus segera mengambil keputusan mengenai keberangkatan kapal guna menghindari titik pusat typhoon apabila kapal berangkat lebih awal tanpa menunggu instruksi dan keputusan Superintendent.

Melakukan pertimbangan mengenai keberangkatan kapal juga pemeriksaan mengenai kondisi kapal yang pada saat itu plat pada windlass dalam keadaan tidak baik. Harus dilakukan maintenance atau lashing dengan cara dilakukannya welding dan painting untuk meyakinkan bahwa plat tersebut sudah dalam keadaan baik atau maintained, tidak mudah rusak dan lepas ketika mendapat tekanan dari tingginya gelombang saat menghadapi cuaca buruk. Apabila kapal dalam posisi yang dekat dengan titik pusat typhoon yaitu 180 mil dan berada pada posisi dangerous semi-circle bagi kapal hingga merusak plat pada windlass, ini dikarenakan tidak dilakukannya pemeriksaan dan lashing pada platform tersebut.

Untuk menghadapi cuaca buru (typhoon), terdapat alternatif pemecahan masalah, yaitu:

Pertama, melaksanakan bridge resource team management untuk melakukan perencanaan strategi mengenai penentuan posisi aman yaitu posisi tujuan akhir kapal atau jarak aman kapal dari 
titik pusat typhoon. Mengidentifikasi karakteristik typhoon tentang kecepatan pergerakan typhoon, tekanan yang disebabkan, kecepatan angin, kondisi laut dan arusnya, kabut dan awan.

Melakukan perkiraan posisi typhoon yang terus bergerak mendekati daratan setiap 6 jam apabila kapal masih berada dalam jarak yang aman yaitu $300 \mathrm{mil}$, terutama kemungkinan adanya bahaya typhoon dengan tindakan berjaga-jaga dan memutuskan waktu keberangkatan kapal mengetahui kondisi kapal yang sudah tidak baik dengan kecepatan tertingginya hanya 10 knots. Oleh karena itu keberangkatan kapal harus dilaksanakan sesuai dengan keputusan Nakhoda ketika melaksanakan bridge resource team management agar kapal segera berangkat untuk bergerak menuju shelter area dan berada pada jarak yang aman dari titik typhoon sehingga kapal tidak mengalami kerusakan juga tidak menghambat operasional kapal.

Nakhoda juga perlu mengadakan briefing kepada awak yang berada di atas kapal mengenai kabar cuaca yang diterima sesegera mungkin agar awak dapat segera mengamankan barang-barang dikapal yang mudah berpindah tempat atau mudah rusak atau mengakibatkan kerusakan pada kapal. Nakhoda juga harus mengedukasi bridge team tentang cuaca buruk, persiapan-persiapan yang dilakukan, memposisikan kapal saat menghadapi cuaca buruk, peraturan-peraturan yang mengatur pergerakan kapal ketika bernavigasi, teknik-teknik yang dilakukan ketika kapal berlayar untuk menghindar dari dampak cuaca buruk atau typhoon

Kedua, nahkoda mengadakan pengawasan langsung atau berada di anjungan untuk mendampingi para Perwira jaga dan juru mudi atau bridge team untuk mengambil alih semua pimpinan dibawah perintahnya. Nakhoda harus melakukan pengawasan ke anjungan secara berkala untuk mengetahui posisi kapal dan jarak kapal apakah sudah berada dijarak yang aman atau perlu dilakukan perubahan haluan untuk pergerakan kapal.

Ketiga, nahkoda melakukan pemeriksaan sebelum memulai pelayaran terhadap kondisi pengikatan pada alat-alat keselamatan termasuk pilot ladder dan semua lashing materials yang ditempatkan pada setiap platform atau plat khususnya paling mudah untuk rusak apabila mendapat tekanan yang cukup besar dari luar seperti plat pada windlass. Memastikan semuanya dalam kondisi yang aman untuk melakukan sebuah pelayaran memasuki cuaca buruk, sehingga ketika kapal berlayar pengikatan pada muatan dan alatalat keselamatan dapat bertahan sampai kapal tiba di pelabuhan tujuan dengan selamat. Melakukan lashing atau maintenance terhadap dek, mengganti plat-plat yang sudah dalam keadaan tidak baik atau berkarat, melakukan welding kembali terhadap plat-plat tersebut dan di cat kembali agar deck terlihat bagus dan maintained dengan baik untuk memastikan bahwa kapal sudah dalam keadaan baik dan fit untuk menghadapi cuaca buruk.

Adapun evaluasi pemecahan masalah sebagai berikut:

1. Melaksanakan bridge resource team management untuk melakukan perencanaan dan strategi mengenai penentuan posisi aman yaitu posisi tujuan akhir kapal atau jarak aman kapal dari titik pusat typhoon. Mengidentifikasi karakteristik typhoon tentang kecepatan pergerakan typhoon, tekanan yang disebabkan, kecepatan angin, kondisi laut dan arusnya, kabut dana wan, posisi dan perkiraan posisi typhoon yang terus bergerak mendekati daratan setiap 6 jam agar kapal berada dalam jarak yang aman yaitu 300 mil. Melakukan tindakan berjaga-jaga dan memutuskan waktu keberangkatan kapal mengetahui kondisi kapal yang sudah tidak baik dengan kecepatan tertingginya hanya 10 knots.

Oleh karena itu keberangkatan kapal harus dilaksanakan sesuai dengan keputusan Nakhoda. Apabila bridge resource team management maka kapal harus berangkat untuk bergerak menuju shelter area dan berada pada jarak yang aman dari titik typhoon sehingga kapal tidak mengalami kerusakan dan tidak menghambat operasional kapal. Nakhoda juga perlu mengadakan briefing kepada crew yang berada diatas kapal mengenai kabar cuaca yang diterima sesegera mungkin agar crew dapat segera mengamankan barang-barang dikapal yang mudah berpindah tempat atau mudah rusak atau mengakibatkan kerusakan pada kapal. Selain itu, nakhoda juga harus mengedukasi bridge team pengetahuan tentang cuaca buruk, persiapanpersiapan yang dilakukan, memposisikan kapal saat menghadapi cuaca buruk, peraturan-peraturan yang mengatur pergerakan kapal ketika bernavigasi, teknik-teknik yang dilakukan ketika kapal berlayar untuk menghindar dari dampak cuaca buruk atau typhoon .

Keuntungan:

Bridge resource team management yang dilakukan seperti ini hanya membutuhkan waktu yang singkat dan setiap perwira kapal akan memahami dan mengetahui semua persiapanpersiapan yang dilakukan kapal ketika akan menghadapi cuaca buruk atau typhoon, dimulai dari penerimaan berita cuaca buruk, mengidentifikasi karakteristik typhoon, tindakan darn antisipasi apa yang harus dilakukan seperti merencanakan rancangan pelayaran tentang Shelter area yaitu posisi akhir kapal dari perjalanan untuk menghindari dan menjauh dari titik pusat typhoon. 


\section{http://ejournal.stipjakarta.ac.id/index.php/pcsa}

Dengan menjalankan bridge recource team management maka akan segera diberangkatan kapal pada saat typhoon sudah bergerak sehingga kapal dan terhindar dari cuaca buruk atau typhoon terutama terhindar dari kecelakaan pelayaran.

Keugian:

Memerlukan waktu yang lama karena memerlukan persiapan mengenai teori-teori, prosedur-prosedur yang telah diterapkan oleh perusahaan, dan juga butuh penjelasan yang lebih detail dikarenakan bridge team bukan hanya saja perwira kapal namun juga Jurumudi yang ikut dalam pelaksanaan bridge resource team management, dan mengharuskan mualim 2 untuk membuat rancangan pelayaran, dan alat-alat navigasi untuk keberangkatan kapal. Hal ini tidak optimal kalua dilaksanakan pada saat sudah menghadapi musibah/kecelakaan.

2. Nahkoda mengadakan pengawasan langsung atau berada di anjungan untuk mendampingi para Perwira jaga dan Juru mudi atau bridge team untuk mengambil alih semua pimpinan dibawah perintahnya, Nakhoda juga harus melakukan pengawasan ke anjungan secara berkala untuk mengetahui posisi kapal dan jarak kapal apakah sudah berada dijarak yang aman atau perlu dilakukan perubahan haluan untuk pergerakan kapal.

Keuntungan :

Dalam metode pemecahan ini, keuntungan yang diperoleh adalah nakhoda mengetahui seluruh persiapan-persiapan yang dilakukan sebelum kapal berangkat untuk menghindari typhoon dan ketika kapal berlayar ketika menghadapi cuaca buruk atau typhoon

Kerugian :

Metode ini memakan waktu nakhoda untuk memeriksa seluruh bagian, di deck dan di anjungan.

3. Nahkoda melakukan pemeriksaan sebelum memulai pelayaran terhadap kondisi pengikatan pada alat-alat keselamatan termasuk Pilot ladder dan semua lashing materials yang ditempatkan pada setiap platform atau plat khususnya paling mudah untuk rusak apabila mendapat tekanan yang cukup besar dari luar seperti plat pada windlass. Memastikan semuanya dalam kondisi yang aman untuk melakukan sebuah pelayaran memasuki cuaca buruk, sehingga ketika kapal berlayar pengikatan pada muatan dan alat-alat keselamatan dapat bertahan sampai kapal tiba di pelabuhan tujuan dengan selamat. Melakukan lashing atau maintenance terhadap dek, mengganti plat-plat yang sudah dalam keadaan tidak baik atau berkarat, melakukan welding kembali terhadap plat-plat tersebut dan di cat kembali agar deck terlihat bagus dan maintained dengan baik untuk memastikan bahwa kapal sudah dalam keadaan baik dan fit untuk menghadapi cuaca buruk.

Keuntungan :

Plat-plat yang rusak atau dalam keadaan yang tidak baik dapat dilakukan perbaikan dan perawatan lebih awal sehingga kapal siap menghadapi cuaca buruk sehingga keberangkatan kapal tidak terlambat perbaikan dan perawatan secara rutin agar kapal terutama bagian dek selalu terpantau dan dalam keadaan yang fit atau baik.

Kerugian:

Perawatan dan perbaikan yang dilakukan hanya sekedar menghadapi typhoon sifatnya terburu-buru dan tidak efisien karena hanya dilakukan waktu yang singkat atau hanya satu sampai dua hari.

\section{KESIMPULAN}

Berdasarkan penjabaran yang telah peneliti kemukakan pada sebelumnya, dapat disimpulkan sebagai berikut:

1. Upaya mengatasi typhoon dalam pelayaran.

Nakhoda dan seluruh awak kapal tidak siap menghadapi datangnya typhoon yang tidak diperkirakan sebelumnya dalam pelayaran, sehingga tidak mempersiapkan melaksanakan bridge resource team management untuk melakukan perencanaan strategi mengenai penentuan posisi aman yaitu posisi tujuan akhir kapal atau jarak aman kapal dari titik pusat typhoon, mengidentifikasi karakteristik typhoon tentang kecepatan pergerakan typhoon, tekanan yang disebabkan, kecepatan angin, kondisi laut dan arusnya, kabut dan awan, posisi kapal dan perkiraan posisi typhoon yang terus bergerak mendekati daratan setiap 6 jam apabila kapal masih berada dalam jarak yang aman yaitu 300 mil.

Nakhoda tidak segera mengmbil keputusan memberangkatkan kapal bergerak menuju shelter area dan berada pada jarak yang aman dari titik typhoon sehingga kapal tidak mengalami kerusakan, tidak menghambat operasional kapal dan tidak membahayakan keselamatan pelayaran. Nakhoda juga tidak mengadakan briefing kepada seluruh awak kapal mengenai kabar cuaca yang diterima sesegera mungkin agar awak kapal dapat segera mengamankan barang-barang dikapal yang mudah berpindah tempat atau mudah rusak atau mengakibatkan kerusakan pada kapalTentang lashing dan kondisi plat yang mudah berpindah tempat maupun rusak saat menghadapi typhoon (cuaca buruk).

2. Pemeliharaan dan perawatan kapal.

Seluruh awak kapal termasuk nakhoda mempunyai kontribusi sesuai dengan tugasnya tidak melakukan perawatan dan pemeliharan kapal secara keseluruhan. Lebih khusus tidak dilakukan 
pemeliharaan dan perawatan kapal terhadap windslass, sehingga ketika terjadi typhoon sehingga ketika terjadi typhoon banyak plat-plat yang rusakdan terlepas. Nakhoda dan awak kapal belum memastikan bahwa setiap plat yang berada di dek diperiksa untuk meyakinkan bahwa semua dalam keadaan secured atau dalam keadaan lashings yang baik.

Kemudian saran yang dapat peneliti berikan yaitu:

a. Untuk pihak kapal.

Para Perwira kapal terutama Nahkoda diharapkan untuk lebih teliti dan cepat ketika mengambil keputusan dalam perencanaan strategi untuk menghindari cuaca buruk atau typhoon dengan dilaksanakan bridge resource team management yang dilakukan bersama dengan para Perwira Jaga untuk keberangkatan kapal guna menjauh dari titik pusat typhoon. Nakhoda juga harus mengedukasi bridge team pengetahuan tentang cuaca buruk, persiapan-persiapan yang dilakukan, memposisikan kapal saat menghadapi cuaca buruk, peraturan-peraturan yang mengatur pergerakan kapal ketika bernavigasi, teknik-teknik yang dilakukan ketika kapal berlayar untuk menghindar dari dampak cuaca buruk atau typhoon b. Untuk pihak perusahaan.

Perusahaan pelayaran harus bisa meyakinkan superintendent agar tidak memaksakan kapal bertahan di anchorage, seharusnya pihak perusahaan harus mengambil keputusan yang tepat dan cepat juga menyetujui perkiraan dan perhitungan yang telah dilakukan Nakhoda untuk menghindari kecelakaan pelayaran.

\section{DAFTAR PUSTAKA}

[1] Campbell, John. 1988. Global Maritime Distress Safety (understanding the GMDSS the new marine communication). London.

[2] Darul Prayogo dkk. 2019. Optimalisasi Perawatan Alat-alat Lashing Container Guna Menunjang Bongkar Muat di MV PAC ANTLIA .Jurnal Mitra Manajemen (online) Vol 3. No. 6.

[3] Hasugian, Harnoli. 2017. Penentu Faktor Dominan Penyebab Kecelakaan di Kesyahbandaran Utama Tanjung Priok. Albacore. Vol 1. No. 3.

[4] Her Majesty Stationary Office. 1980. Meteorology for Mariners Second Impression. London.

[5] International Maritime Organizatioan (IMO). 2001. Safety of Life at Saa (SOLAS) Consolidated Edition. London.
[6] International Labour Organization (ILO). 2000. IMARE (Ketentuan ILO mengenai Pencegahan Kecelakaan di Atas Kapal Laut dan di Pelabuhan). London.

[7] Komite Keselamataan Transportasi Nasional. 2020. Laporan Investigasi Kecelakaan Transportasi dan Monitoring Rekomendasi Keselamatan Transportasi. Jakarta.

[8] Prabu Aditya dkk. 2018. Kajian Kondisi Atmosfir di Wilayah Indonesia Saat Periode Aktif-nya Badai Tropis KAI-TAK. Proseding Seminar Nasional Fisika dan Aplikasinya. Gema Maritim Vol 13. No.1

[9] Sekolah Tinggi Ilmu Pelayaran. 1984. Modul Ilmu Cuaca Untuk Strata-A. Jakarta.

[10] Hasugian, Sereti dkk. 2017. Penelitian Karakteristik Kapal di Perairan Indonesia Berda-sarkan Investigasi KNKT. Warta Penelitian Perhubungan Vol 29 No. 2.

[11] _ 2004. Standard Marine Communicatioan Pharases (SMCP). London.

[12] Subandi. 2011. Pengaruh Lanina Terhadap Pelayaran dan Upaya Mengatasi Keselamatan Kapal di Samudera Indonesia. Gema Maritim. Vol. 13. No. 1.

[13] Trans Asia Consultant. 2009. Laporan Akhir Hasil Kajian Analisis Tren Kecelakaan Transportasi Laut Tahun 2003-2008. Jakarta.

[14] International Convention Collision Regulation 1972 dan Amandemen 2010

[15] Sekolah Tinggi Ilmu Pelayaran. 2001. Diktat Pemutakhiran (updating) STCW Amandemen 1995 mengenai watch keeping deck (terjemahan). Jakarta.

[16] Suara. Com. 28 November 2016, Menteri Perhubungan, Kecelakaan Kapal.

[17] https://www.kabar penumpang. 4 Maret 2016, Bayu Mardianto. Diunduh 17 Juli 2020. 